\title{
Correspondence
}

\section{Compulsory admission and suicide}

Sir: John Crammer (Psychiatric Bulletin, December 1998, 22, 769-770) used three case histories of patients dying by suicide to illustrate care issues. Psychological autopsies, I believe, are an essential part of modern care - not to mention research - and his reference to them is to be applauded. However, the dreaded retrospectroscope' is notorious for deception. If a suicidal patient is told to 'turn right' and they shortly after kill themselves, then it can appear that they should have been told to 'turn left'. Similarly outpatients who kill themselves, in retrospect, may appear to have had indications for in-patient care.

Despite the vogue for outcome-orientated medicine and audits of critical incidents, I am unaware of any reasonably scientific research examining the efficacy of either in-patient care or involuntary admission in respect of suicide prevention. However, Crammer suggests the establishment of a commission on the use and limits of compulsion in medicine with community involvement including churchmen, lawyers, trade unionists and more. The inference is that more involuntary care may reduce suicides.

I have no doubt that on occasion both hospitalisation and involuntary care are lifesaving. However, I also suspect that at times these measures are harmful. Therapeutic relationships may be damaged and the mode of care may deter patients from seeking help in the future. The price of reducing short-term risk may be that of increasing long-term risk. In addition, paternalistic care can foster regression. I suspect that establishment of the commission as called for by Crammer may be a wonderful exercise in democracy producing yet more overly simplistic recommendations that head us in the wrong direction. However, a strong case can be put for rigorous scientific investigation of the efficacy of both in-patient care and involuntary care for suicidal people. Further, I will be presumptuous and suggest the question should not be 'Do these measures help?' but instead 'For which types of patients and under what circumstances do these measures have beneficial and negative effects?

Chris CANTOR, Senior Research Psychiatrist, Nathan Campus, Griffith University. Brisbane, Queensland 4111, Australia

\section{Nature or degree}

Sir: Gralton (Psychiatric Bulletin, February 1999, 23, 114) makes an important point in regard to Mental Health Review Tribunals. This same point was recently the subject of a judicial review.

A patient suffering from paranoid schizophrenia and detained under Section 37/41 Mental Health Act 1983 was refused a conditional discharge by a tribunal. At the time it was said that he was not suffering from positive or negative symptoms of his paranoid schizophrenia. The responsible medical officer argued that the patient did suffer from a mental disorder of a nature, but not of a degree, which warranted his continuing detention in hospital. The tribunal agreed and refused his discharge.

In R. $v$. Mental Health Review Tribunal for South Thames region ex-parte Smith (The Times, 9 December 1998), the court considered an appeal against the refusal of the tribunal to discharge the patient. The court rejected the appeal. It was said that it was lawful to continue to detain someone in hospital if the nature of the mental disorder continued to warrant it. Although the patient's condition was thought to be in remission, and therefore the degree of the condition did not warrant continuing detention, the nature of the illness meant that he would be liable to relapse and this was sufficient in itself to warrant continuing in-patient treatment.

I would suggest that this judicial review has gone a long way to clarify this frequently debated point.

MARTIN LOCK, Consultant Forensic Psychiatrist, Three Bridges Regional Secure Unit, Uxbridge Road, Southall, Middlesex UB1 3EU

Sir: Szmulker \& Holloway (Psychiatric Bulletin, November 1998, 22, 662-665) provide a provocative contribution to the current debate on reform of mental health legislation. Their antidiscriminatory stance in arguing for an Incapacity Act to apply equally to patients with mental and physical disorders is attractive.

However, its effect would be to deny to patients treatment which any reasonable layperson would say was desperately needed. The proposed definitions of incapacity they quote, that is, being unable by reason of mental disability to make a decision on the matter in question or being unable to communicate a decision, are tests of "understanding not wisdom" (Law Commission. 
1995). Thus, a patient able to make and communicate a decision to refuse essential treatment on the basis of a delusional belief that the doctors were trying to harm him or her or that supernatural forces would cure them, would pass the capacity test. Few individuals with mental disorders fail such tests (Appelbaum \& Grisso, 1995).

A necessity to appreciate the implications of accepting or rejecting a course of action could be added to the definition. However, this might be imprecise, and would still not include suicidal patients who refused life-saving interventions in the knowledge that they would die, or patients with mania who realised that treatment would remove their feelings of elation and power.

Rather than being a 'solution for our times', the proposals would actually discriminate against such patients, in denying them access to treatment because of their psychiatric symptoms and causing greater 'incapacity'.

Appelbaum, P. S. \& Grisso, T. (1995) The Macarthur Treatment Competence Study 1: Mental illness and competence to consent to treatment. Law and Human Behavior, 19, 127-148.

LAW CoMmission (1995) Mental Incapacity (Law Commission Report 231). London: HMSO.

S. P. DAVIES, Specialist Registrar in Psychiatry, Whitchurch Hospital, Cardiff

\section{Model of forensic psychiatric community care}

Sir: We read the paper by Whittle $\&$ Scally with interest (Psychiatric Bulletin, December 1998, 22, 748-750). Unlike many forensic services, South Thames West has had a community forensic service for over 10 years and only since 1991 has had its own medium secure beds. In 1995 a consultant was appointed to re-organise open forensic beds and to develop an outreach forensic service to meet demand in the furthest points of the region (West Sussex). The open forensic beds provide a seamless parallel service for community forensic patients requiring nonsecure admission and for medium secure patients requiring a trial of non-secure hospital care.

The outreach service is integrated with local psychiatric teams in West Sussex who retain responsibility for patients requiring crisis intervention. Requests for secure beds go directly to the medium secure unit teams. One day a week, the outreach service provides assessment and specialist packages of forensic care at West Sussex clinics or wherever appropriate including in-patient wards, probation offices etc. Setting up security systems at the out-patient sites has been important and staff have to be vigilant. This encourages joint assessment, which best meets service users' complex needs. Our multidisciplinary team is more comprehensive than that described by Whittle \& Scally - consisting of a social worker, psychologist, consultant, senior registrar, senior house officer and a community psychiatric nurse. Over five referrals monthly come from local psychiatric teams, the probation service, social services, magistrate's courts and prisons. A referral and management meeting occurs weekly. Referrals are appropriate but all bodies are becoming more assertive in seeking forensic advice.

We have encountered similar issues as Whittle \& Scally in working with secondary services. We remain concerned that dangerous patients are construed unconsciously by referrers as automatically transferred to forensic supervision rather than for assessment leaving potentially hazardous gaps in the care plan.

Informal feedback from the outreach is positive. The two models of service provided by this team may offer food for thought to services providing secure units only.

CATHERINe KINANE, Senior Registrar and ANNIE BARTLETT Senior Lecturer and Consultant in Forensic Psychiatry, St George's Hospital Medical School, Cranmer Terrace, Tooting. London SW17 ORE

\section{Parent satisfaction with receiving information in an attention-deficit hyperactivity disorder (ADHD) clinic}

Sir: We would like to report a survey which we did on 97 consecutive couples who had a child on the waiting list for an attention-deficit hyperactivity disorder (ADHD) clinic. These couples were consecutively and randomly assigned to receive information about the clinic and ADHD.

After the first interview, the patients were given a service user satisfaction questionnaire (Attkisson \& Greenfield, 1994) which is well standardised and validated and two questions about receiving information about ADHD and the clinic were added. There was good internal consistency among the items on the questionnaire and the two added questions.

Of the 49 couples randomly assigned to group meetings (five groups were held at monthly intervals with 10 couples invited to each) 29 attended and 24 completed the questionnaires.

Of the 48 couples sent a mail out, five said they had not received it and four said they had not read it. Twenty-four completed the consumer satisfaction questionnaire.

In comparing the patient questionnaires there was no difference in patient satisfaction using ANOVA between those who had received the 